\title{
MUERTE Y LITERATURA EN L'ÉNIGME DU RETOUR DE DANY LAFERRIÈRE Y THE ART OF DEATH DE EDWIDGE DANTICAT ${ }^{1}$
}

\author{
Death and Literature in L'énigme du retour by Dany Laferrière and The Art of Death by Edwidge \\ Danticat
}

\author{
Lucía Stecher Guzmán ${ }^{\mathrm{I}}$ \\ ${ }^{\mathrm{I}}$ Universidad de Chile, Chile. luciastecher@gmail.com
}

\section{RESUMEN}

Este artículo propone una lectura conjunta de The Art of Death. Writing the Final Story (2017) de Edwidge Danticat y L'énigme du retour (2009) de Dany Laferrière, escritores que forman parte de la diáspora haitiana contemporánea y que tienen una importante trayectoria literaria. En los dos libros analizados juega un rol central la representación del duelo por la muerte de uno de los progenitores, la reflexión sobre la propia producción literaria y la pregunta por cómo representar Haití desde la diáspora. El artículo se detiene en el vínculo que se establece en estos textos entre la representación de la muerte y los proyectos éticos y estéticos particulares de sus autores, muchas veces tensionados por su posición diaspórica que no excluye su atención e interés por la realidad haitiana contemporánea.

PALABRAS CLAVE: Edwidge Danticat; Dany Laferrière; duelo; muerte; diáspora.

\section{ABSTRACT}

This article focuses on two texts written by two important contemporary authors from the Haitian diaspora: The Art of Death. Writing the Final Story (2017) by Edwidge Danticat and L'Énigme du retour (2009) by Dany Laferrière. Both books reflect on mourning the death of a parent, the authors' own literary production, and the question of how to represent Haiti from abroad. The article analyzes how each book establishes connections between the representations of death and mourning and the authors' ethical and aesthetic projects, centered around Haitian issues and written from diasporic positions.

KEYWORDS: Edwidge Danticat; Dany Laferrière; mourning; death; diaspora.
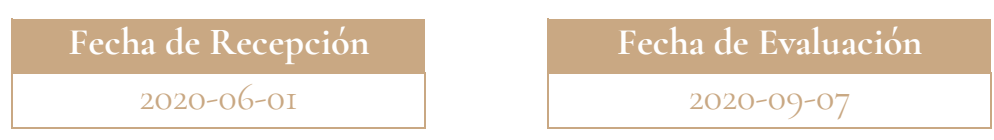

\footnotetext{
${ }^{1}$ Este artículo forma parte de los resultados obtenidos en el Proyecto Fondecyt $n^{\circ}{ }_{1190607}$, dirigido por Lucía Stecher Guzmán. La autora agradece también al proyecto "Connected Worlds: the Caribbean, Origin of Modern World" financiado por el programa de investigación e innovación de la Unión Europea Horizon 2020 (Maria Sklodowska Curie Grant Agreement nº 823846).
} 
I am not fully known to myself, because part of what I am is the enigmatic traces of others. ${ }^{2}$ (Judith Butler, Precarious Lifes)

\section{INTRODUCCION}

Dany Laferrière y Edwidge Danticat son dos de los escritores de la diáspora haitiana más reconocidos y premiados en la actualidad. Ambos cuentan con una vasta obra literaria y con un posicionamiento intelectual público en los países en que viven y en el espacio simbólico de las diásporas caribeñas. En Estados Unidos, país al que llegó como migrante a los I2 años, Edwidge Danticat se ha convertido en un referente ineludible en relación con los temas vinculados a la migración y la historia de su país de origen. Laferrière, por su parte, llegó a Canadá a los 23 años, huyendo de la dictadura de Baby Doc, ${ }^{3}$ que acababa de asesinar a un amigo suyo con quien trabajaba como periodista. Dos décadas antes su padre se había exiliado tras ser perseguido por Papa Doc. Después de vivir muchos años en Norteamérica (Canadá y Estados Unidos), Dany Laferrière -cuyo nombre de nacimiento es Windsor-se trasladó a París, donde actualmente reside y desde 2015 es miembro de la Academia Francesa de la Lengua.

En este artículo me interesa proponer una lectura conjunta de dos de sus publicaciones recientes, que abordan experiencias de duelo por la muerte de un progenitor y desde allí abren un conjunto de reflexiones en torno a la relación entre muerte y literatura. Se trata de The Art of Death. Writing the Final Story (2017) de Danticat y de L'énigme du retour (2009, Premio Médicis) de Laferrière. La enfermedad y muerte de la madre en el libro de Danticat y la noticia de la muerte del padre en la novela de Laferrière son el punto de partida de textos centrados en el esfuerzo por recuperar las huellas e historias de estos progenitores. La ausencia definitiva que significan estas muertes viene precedida por biografías marcadas por largas separaciones familiares impuestas por contextos de migración y exilio: cuando Edwidge Danticat tenía cuatro años su madre partió a Estados Unidos para reunirse con su marido, que ya llevaba dos años ahí. Recién a los doce años la futura escritora pudo reunirse con su familia en Nueva York. L'énigme du retour ha sido leída como una autoficción (Mathis-Moser 255-264), concepto con el que se ha descrito gran parte de la obra de

\footnotetext{
2 "No soy totalmente consciente de mí porque parte de lo que soy lleva la huella enigmática de los otros" (trad. de la autora).

${ }^{3}$ La dictadura de los Duvalier en Haití comprende el mandato de François Duvalier entre 1957 y i97r y el de su hijo JeanClaude de 197r hasta su exilio en 1986. Los apelativos de Papa Doc y Baby Doc hacen referencia a la profesión médica del padre y a la juventud del hijo al momento de heredar el gobierno.
} 
Laferrière. ${ }^{4}$ Este comparte con el narrador-protagonista homónimo la experiencia de tener un padre que partió al exilio cuando él era niño. En ambos libros, la muerte de los padres revive en estos hijos el peso de la ausencia durante la primera separación y los dolores provocados por su propia emigración y desarraigo. La expresión haitiana lót bò dlo, "al otro lado del agua", refiere tanto a la muerte como a la migración; y la separación que resulta de ellas es, en palabras de Danticat, "earth shattering", "devastadora" (Danticat, "Lòt Bò Dlo: The Other Side of the Water" 268).

En The Art of Death y L'énigme du retour, la pregunta por la posibilidad de hablar de la muerte -y la vida- de los progenitores es puesta en relación con un conjunto de reflexiones sobre el rol de la literatura en momentos de crisis en la vida de una persona y de un colectivo, país o sociedad. La muerte de la madre o el padre conduce a una interrogación por los legados familiares, por las herencias materiales, simbólicas, conscientes e inconscientes que dejan los progenitores. Dichos interrogantes además se proyectan al ámbito literario, lugar en el que se iluminan relaciones con escritores y escritoras percibidos como ancestros. La orfandad, en estos textos, es vivida a un nivel doble: respecto de los padres biológicos y de los literarios. Los sujetos de enunciación interrogan así sus relaciones de filiación familiares y simbólicas. En este sentido es posible leer estos libros como relatos de filiación, de acuerdo con la propuesta de Dominique Viart. ${ }^{5}$ En esta lectura hacemos extensivo el "fenómeno de la búsqueda de la ascendencia" (Viart 5 ) al campo literario.

En L'énigme du retour vemos una superposición de la figura de Aimé Césaire-considerado como padre literario del Caribe francófono-, con la del padre del narrador: ambos están muertos y arrojan sombras potentes sobre el protagonista que se relaciona ambivalentemente con sus ausencias. ${ }^{6}$ Como señala Francisco Aiello en un artículo sobre esta novela, "resulta significativo que Aimé Césaire haya fallecido el i7 de abril de 2008, es decir, un año antes de la aparición de la novela de Laferrière que nos ocupa. De manera que esta escritura signada por el duelo parece estar

\footnotetext{
${ }^{4}$ Laferrière, por su parte, se ha referido a su obra como un libro único, La autobiografía americana, que se divide en dos ciclos: norteamericano y haitiano. Los libros del primer ciclo reconstruyen la experiencia urbana en Norteamérica y los del segundo la vida en Haití (Biholaru 67).

5En 1996 Dominique Viart propuso el concepto de relato de filiación para dar cuenta de "un conjunto de textos que no provienen de la novela, ni de la biografía, ni de la autobiografía, pero que sin embargo esbozan un espacio entre ellas" (4). Viart observa a partir de los años go el retorno de la literatura francesa a la cuestión del sujeto —desplazado durante tres décadas de hegemonía del formalismo-, pero con importantes diferencias en relación con su posición en autobiografías, memorias y novelas de periodos anteriores. Para Viart, el impacto del sicoanálisis al establecer la dificultad del sujeto de acceder a su inconsciente y a su vida interior, lleva a la creación de ficciones personales y de relatos que dan cuenta de una búsqueda de la ascendencia.

${ }^{6}$ El título del libro de Laferrière hace referencia a The Enigma of Arrival de V.S. Naipaul. También a nivel de los capítulos encontramos alusiones a ese mismo libro: mientras su último capítulo se titula "The Ceremony of Farewell", uno de los capítulos del final del libro de Laferrière se llama "La cérémonie des adieux". Pese a tales referencias a Naipaul, es indudable que el principal autor con quien dialoga L'énigme du retour es Aimé Césaire y que su principal intertexto es el Cahier d'un retour au pays natal.
} 
motivada por ambas muertes: la del padre y la de la figura tutelar de la literatura antillana de expresión francesa" ("La reelaboración..." 15-16).

Si bien en The Art of Death la autora recurre a distintas escritoras y escritores para profundizar en las formas de escribir sobre la muerte, las más citadas son escritoras afroestadounidenses, en especial Toni Morrison. La pregunta por las relaciones con antecesores y contemporáneos en el campo del arte ya aparecía con fuerza en el libro anterior de ensayos de Danticat, Create Dangerously, publicado en zoro. Ahí la autora reflexiona sobre su condición de huérfana literaria provocada principalmente por la censura dictatorial que silenció a muchos escritores y los proscribió de las aulas escolares y el espacio público haitiano en general. Es a partir de la migración a Estados Unidos y las experiencias de discriminación que la llevaron a refugiarse en la biblioteca pública de Brooklyn, que Danticat pudo encontrarse con esos padres y madres literarias que le permitieron inscribir su vocación en el marco de una tradición mayor: una genealogía que la habilitaba como escritora. Para ella, la figura femenina más importante en ese contexto fue Marie Vieux-Chauvet, autora del primer libro abiertamente crítico de la dictadura de Duvalier y cuya obra miró a la sociedad haitiana de su época desde una perspectiva feminista (Clitandre 174). Además de conectarla con los libros haitianos de la biblioteca, la migración le permitió a Danticat acceder a la producción de escritoras afroestadounidenses, una tradición que resultó fundamental para el surgimiento de autorías de la diáspora afrocaribeña en Estados Unidos (Stecher 2016).

\section{LOS LEGADOS: LA MALETA Y LOS CASSETTES}

La muerte de los padres provoca en los narradores de L'énigme du retour y The Art of Death un sentimiento de orfandad en el que pesan también los silencios y el desconocimiento de muchos aspectos de sus vidas. De acuerdo con Viart, los relatos de filiación surgen precisamente como respuesta a "una ausencia de transmisión" y proceden "a la inversa del relato biográfico tradicional y de su cronología lineal. El relato de filiación retrocede en el tiempo. A menudo comenzando con una muerte, la del padre ... la de la madre ... o la de algún otro familiar, el texto parte del presente y va colectando poco a poco recuerdos, relatos recibidos, objetos que permitirán decodificar el pasado" (Viart 8). En los libros de Danticat y Laferrière, los hijos reciben de sus padres objetos en los que depositan algo de sí mismos. Se trata de objetos-legados que portan algo que los padres consideraron valioso, pero cuyos modos de recepción presentados en los libros simbolizan las dificultades que enfrenta la transmisión de esas herencias. 
La llamada que despierta al narrador-protagonista de L'énigme du retour y que "coupe la nuit en deux"7 (I3) marca el inicio de la novela y del viaje que emprende el protagonista luego de recibir la noticia de la muerte de su padre en un hospital en Brooklyn. Los primeros desplazamientos los hace en un escenario canadiense atravesado por el frío y la soledad, que contrastan con sus recuerdos del calor de Haití. Luego parte a Nueva York, donde participa del entierro de su padre. Allí ocurren dos escenas claves que muestran la complejidad de la transmisión de las herencias y legados. En un primer momento, los tíos llevan al narrador protagonista a visitar al único amigo de su padre, un peluquero. Este, al ver a Dany, le dice que es muy parecido a su padre, pero no físicamente, sino que se nota que "vous êtes taillés du même arbre"8 (65). Poco después Dany se sienta exactamente en la silla que usaba su padre, al lado del baño. Este capítulo establece una continuidad entre padre e hijo y evidencia la huella que la efímera presencia del primero ha dejado en la vida del segundo.

En cambio, el siguiente capítulo muestra la dificultad o incluso la imposibilidad de recuperar un legado. Los tíos de Dany lo llevan al Chase Manhattan Bank para que rescate una maleta del padre que se asume destinada a él. La coincidencia de nombres entre padre e hijo facilita el ingreso del segundo a la bóveda. Pero una vez ahí, frente a la maleta resguardada, Dany y sus tíos no consiguen adivinar la clave para abrir el candado. Esta situación, que podría ser frustrante, constituye un alivio para el narrador: "Cette valise m'attendait. / Il a fait confiance au réflexe de son fils. / Ce qu'il ne savait pas / (tais-toi donc, on n'apprend rien à un mort) / c'est que le destin ne se transmet pas de père en fils. / Cette valise n'appartient qu'à lui. / Le poids de sa vie" (70). ${ }^{9}$ En estos versos, la maleta es personificada (ella lo espera) y el sujeto poético la asocia directamente con la intención del padre: "él se fió del reflejo de su hijo". El hijo da con la maleta, pero no la puede abrir, con lo que se libera de tener que cargar con "el peso de su vida". Su figura es para el narrador, la de "un astre trop aveuglant/ pour qu'on puisse le regarder de face" (6I). ${ }^{\text {10 }}$

El relato de filiación que presenta L'énigme du retour está cargado de ambivalencias e incluso contradicciones. El narrador regresa por primera vez a Haití tras la muerte de su padre, porque esta le provoca la necesidad de recuperar su historia. Para eso recurre a la imaginación, a una única foto antigua, y en Haití a los relatos de los amigos y conocidos que va encontrando durante su viaje por

\footnotetext{
7 "La noticia parte la noche en dos" (I7). Las traducciones de L'énigme du retour corresponden al texto en castellano citado en la bibliografía.

8 "está tallado en la misma madera" (74).

9 "Esa maleta me estaba esperando / Se fió del reflejo de su hijo / Lo que no sabía / (calla, nada se le enseña a un muerto) / es que no se transmite el destino de padres a hijos / Esa maleta sólo a él le pertenece / El peso de su vida" (8o).

ro "Un astro demasiado cegador/para poder mirarlo de frente" (71).
} 
la región natal de su progenitor. Hay en él un esfuerzo de reconexión, pero también un rechazo a recibir la herencia paterna. Concuerdo con la interpretación de Ching Selao cuando señala:

De fait, ce qui se présente d'abord comme un retour aux pères à travers le voyage au pays natal s'avère finalement être un détour para lequel Laferrière (nom de l'auteur et du narrateur), d'une part, offre un hommage au poète martiniquais et, d'autre part, exprime son refus de l'héritage paternel, que ce soit celui du destin symbolisé par la valise du père ou le legs littéraire de Césaire. $(\mathrm{I} 64)^{11}$

Otra relación hereditaria, de carácter ominoso, configura el trasfondo del destino compartido por Laferrière padre e hijo: en I97I, al morir François Duvalier, le dejó el gobierno de Haití a su hijo Jean-Claude, quien continuó su dictadura de terror, violencia y corrupción hasta que fue depuesto en 1986. Papa Doc exilió a Laferrière padre, Baby Doc al hijo, ambos por su rol de opositores. ${ }^{\mathrm{I2}}$ Pero si Baby Doc heredó y continuó la dictadura de su padre sin cuestionarla, Laferrière hijo decide ser un exiliado distinto a su padre: no se propone conservar ni la rabia, ni una identidad de revolucionario en el exilio. Como veremos después, el retorno del protagonista a Haití es muy distinto al que podría haber imaginado su padre, que aspiraba, como Césaire, a tener un impacto transformador en su sociedad.

El lugar de la maleta lo ocupan, en The Art of Death, los cassettes que grabó la madre de Danticat al enterarse que le quedaba poco tiempo de vida. Le habían diagnosticado un cáncer que no tenía cura y en la última etapa de su tratamiento decidió suspenderlo. Después de su muerte, Danticat imagina la escena de creación de los cassettes: mientras sus hijos duermen, su madre se sienta a grabarles mensajes. A diferencia de lo que ocurre con la maleta en Laferrière, aquí no existe una clave que impida el acceso al legado de la madre. Pero tampoco se trata de un legado transparente, esos mensajes demandan esfuerzos de traducción e interpretación. Después de cuarenta años en Estados Unidos, la madre de Danticat seguía sin saber más que un par de frases en inglés. En los cassettes habla en creole y deja instrucciones sobre cómo quiere que sean sus hijos, sus nietos, la vida sin ella. Al escribir sobre estas grabaciones, Danticat no solo traduce las palabras de su madre al inglés, sino que interpreta lo que quieren decir algunas expresiones y, sobre todo, busca acercarse a su modo de comprender la vida. Cuando la madre le dice: "Metfanmsouou" (I2), Danticat

\footnotetext{
${ }^{\text {I" }}$ 'De hecho, lo que en un principio se presenta como un retorno a los padres por medio del viaje al país natal se revela finalmente como un desvío a través del cual Laferrière (nombre del autor y del narrador), por una parte, le ofrece un homenaje al poeta martiniqueño y, por la otra, expresa su rechazo a la herencia paterna, ya sea del destino simbolizado por la maleta del padre o el legado literario de Césaire" (trad. de la autora).

${ }_{12}$ "Nous avons chacun notre dictateur/ Lui, c'est le père, Papa Doc./ Moi, le fils, Baby Doc./ Puis l'exil sans retour pour lui./ Et ce retourénigmatiquepourmoi" (271). "Tenemos cada uno nuestro dictador./ Ël, el padre, Papá Doc./ Yo, el hijo, Baby Doc./ Después, el exilio sin regreso él/ Y este regreso enigmático yo" (302).
} 
traduce tanto el sentido literal, "Be your own woman" (I2), como lo que quiere decir, "Be a strong woman" (I2). ${ }^{\text {13 }}$

Los mensajes de los cassettes y los esfuerzos de traducción y decodificación que Danticat despliega, ponen de manifiesto la distancia que se instala entre padres e hijos cuando estos acceden a la educación formal y la cultura estadounidense. A lo largo de todo el libro Danticat aparece como traductora de su madre en el sistema médico y como mediadora entre los mensajes de su madre y los lectores. Más aún, en su acercamiento a la vida y muerte de su madre en un libro en el que reúne las experiencias reales y ficticias de otras personas y autores reconocidos, Danticat busca recuperar para su progenitora la dignidad que siente que el sistema estadounidense le niega. Como migrante haitiana que no habla inglés, la madre requiere de la presencia y traducción de su hija para recibir tratamiento médico. A modo de agradecimiento la enferma le pide a su hija que le regale alguno de sus libros a sus tratantes. Uno de los últimos especialistas que atiende a su madre le dice a su equipo que se trata de una mujer especial porque ha criado a una escritora. Frente a esto Danticat se indigna: "My mother is dying and I write books" ${ }^{14}$ (6, cursivas en el original). La hija demanda la valoración de su madre por lo que ella misma ha sido, y no por la hija que ha criado. Un esfuerzo similar de recuperación de la dignidad de la madre lo vemos en la interpretación que hace la hija del acto de grabación: "The act of writing, or talking about one's death, makes one an active participant in one's life. Those who write, or make cassettes, about dying are not dying passively, so we should not write about them that way" $(20) .^{15}$

Es interesante observar las grandes diferencias que existen en la forma en que las voces enunciadoras de L'énigme du retour y The Art of Death se relacionan con la herencia paterna y materna, respectivamente. Mientras en el primer caso, el hijo parece heredar inconscientemente gestos y elecciones de su padre - "están hechos de la misma madera"- y se alegra de evadir el destino contenido en la maleta, en el segundo la hija reconoce que en todo momento existe una distancia irremontable entre ella y su madre, que busca acortar en parte a través de sus mensajes y la recuperación de fragmentos de su historia. La doble restitución que en la propuesta de Viart realizan los relatos de filiación resulta más evidente en el libro de Danticat que en el de Laferrière. Para Viart, este trabajo de restitución "intenta a la vez compensar una ignorancia y dar voz a aquello que no tuvo acceso a la lengua ni a la narración" (го) y también busca restablecer "la

${ }^{13}$ La traducción literal sería "Sé tu propia mujer" y la segunda "Sé una mujer fuerte" (todas las traducciones de The Art of Death son de la autora).

${ }_{4}$ "Mi madre está muriendo $y$ yo escribo libros".

${ }_{15}$ "El acto de escribir, de hablar de la propia muerte, nos convierte en participantes activos en nuestra propia vida. Los que escriben, o graban cassettes, sobre la muerte no mueren pasivamente y por lo tanto no debiéramos escribir sobre ellos de ese modo". 
existencia a quienes les fue despojada, conferirles una legitimidad perdida, recuperar una dignidad maltratada" (Iо).

Laferrière ve en todo momento a su padre en función de lo que significa para su vida y teme no poder sustraerse a las huellas que ha dejado en él. Danticat procura pensar a su madre como una figura distinta a ella, que tuvo su propia historia antes de que sus vidas se entrecruzaran: "We want to write our mothers not only as our mothers but as people, lovers, women who had a beginning that did not include us but who are now pulling us along with them into their ending" $(\mathrm{I} 35) \cdot{ }^{16}$

\section{"LA MUERTE SOLO PUEDE SER NARRADA EN TERCERA PERSONA": REFLEXIONES SOBRE EL QUEHACER LITERARIO}

Frente al desafío de representar literariamente la muerte, Danticat recurre, en The Art of Death, a un conjunto de textos centrados en este tema. La lectura cercana de pasajes en los que diversos escritores y escritoras hablan de la inminencia de la propia muerte o la de seres queridos le permite a Danticat inscribir su propia búsqueda de lenguaje e imágenes en un universo mayor. Su libro muestra cómo la muerte es, al mismo tiempo, una experiencia absolutamente particular y profundamente universal.

En la posición de enunciación diaspórica de Danticat, hablar de la muerte es también un modo de referirse a la ausencia y de reflexionar sobre la posibilidad de representar experiencias que no se han tenido o que no se tienen de forma cotidiana. Me refiero particularmente a la tensión que atraviesa toda su obra y su posicionamiento autorial por el hecho de haber construido un universo narrativo anclado en el país que dejo a los doce años.

¿Qué perspectiva puede tener una escritora que vive en Estados Unidos de la historia, la cultura y las dificultades que atraviesa Haití? ¿Cómo dar cuenta de la complejidad de la vida haitiana? ¿Cómo recuperar y ficcionalizar su historia sin traicionarla? ¿De qué formas se puede hablar de las vidas de otros sin pretender convertirse en su voz?

Danticat es muy consciente de estos cuestionamientos, que no solo ha recibido a modo de crítica, sino que ha hecho suyos porque constituyen desafíos éticos y estéticos para su producción

\footnotetext{
16 "Queremos escribir sobre nuestras madres no solo en su calidad de madres, sino como personas, amantes, mujeres con un inicio que no nos incluye, pero que ahora nos arrastran con ellas hacia su final".
} 
literaria. Al dedicarse, en su último libro, al tema de la muerte como un reto para la representación, retoma estas preocupaciones ya presentes en su escritura desde su primera novela. ${ }^{17}$

La frase de Ondjatee con que titulo este apartado "Death means you are in the third person"18 (cit. en The Art of Death 28), va en la misma línea de la reflexión de Camus, también citada por Danticat: "In reality there is no experience of death ... it is barely possible to speak of the experience of others deaths" ${ }^{\prime \prime 9}$ (29). Pese a esta imposibilidad radical, la muerte ha sido tematizada por las literaturas de distintas épocas y lugares; cada nuevo esfuerzo por hablar de esta, remite a los anteriores. Me parece que es posible ampliar esta reflexión para pensar las preguntas y desafíos que enfrenta la escritura de Danticat en general y que explicité al principio de este apartado. Quizás responder a la pregunta por cómo se puede hablar de la muerte sin haber muerto, ${ }^{20}$ permite por extensión validar la escritura sobre otras experiencias no vividas directamente. Así como para poder hablar de la muerte de su madre y de la representación literaria de esa "historia final" Danticat recurre a una amplia tradición literaria vinculada al tema de la muerte, también para tematizar la historia, cultura y sociedad haitiana se inserta en el campo mayor de las tradiciones literarias y orales de su país. Es decir, no es una voz solitaria tratando de representar un amplio abanico de experiencias que exceden lo que puede vivirse en forma individual; más bien su punto de partida está situado en un colectivo que comparte un imaginario común y que es capaz de recrear a través de la imaginación experiencias que lo trascienden, como la de la muerte y la de las vidas haitianas.

En The Art of Death, Danticat entrega su testimonio personal sobre el rol que ha tenido y tiene la literatura en su vida, centrándose sobre todo en sus duelos y en cómo suele releer los mismos libros "when living with and writing about death"21 (7). Lectura y escritura constituyen actividades inseparables para enfrentar las pérdidas: "Writing has been the primary way I have

\footnotetext{
${ }^{17}$ En el ensayo "Walk Straight" de Create Dangerously Danticat recuerda las críticas que recibió por Breath, Eyes, Memory, su primera novela. Estas provinieron principalmente de la comunidad haitiana residente en Estados Unidos, que la acusó de contribuir a las representaciones negativas de los haitianos. Esto se debe a que en la novela la protagonista, Sophie, es sometida por su madre a una prueba de virginidad. En respuesta a estas acusaciones Danticat incluye en la segunda edición de la novela -y en el ensayo citado- una carta dirigida a su protagonista en la que le "explica" que no era su intención convertirla en "representativa" de todo lo haitiano.

18 "La muerte solo puede ser narrada en tercera persona".

19 "En realidad no hay una experiencia de la muerte... apenas es posible hablar de la experiencia de la muerte de otros".

${ }^{20}$ En Pays sans chapeau de Dany Laferrière un personaje le pregunta al narrador exactamente eso: "J'aimerais savoir comment vous pouvez écrire à propos des morts quand vous n'avez jamais été mort?" (130). (Me gustaría saber cómo puede escribir de los muertos si nunca ha estado muerto" (trad. de la autora). Francisco Aiello destaca que "Pays sans chapeau es una novela que narra el regreso a Haití tras veinte años de exilio. Esto le brinda al personaje-narrador —-también llamado Laferrière- un reencuentro con su cultura de origen y le permite advertir que su posición frente a ella es próxima a la de un extranjero" ("Elaboraciones..." I69). La continuidad temática entre Pays sans chapeau -que es el país de los muertos según el vudú- y L'énigme du retour es evidente, aunque en la primera la importancia del creole, el vudú y también el humor confieren al texto un tono muy distinto al de la segunda.

2r "cada vez que le ha tocado vivir con y escribir sobre la muerte".
} 
tried to make sense of my losses, including deaths. I have been writing about death for as long as I have been writing"22 (6). La escritura es para Danticat una herramienta fundamental de búsqueda de sentido: "We write about the dead to make sense of our losses, to become less haunted, to turn ghosts into words, to transform an absence into language"23 (29).

El viaje a través de Haití de Dany Laferrière personaje para recuperar las huellas de su padre también puede ser leído como un esfuerzo por transformar una ausencia en lenguaje. Pero el viaje es, a su vez, un recurso que le permite a la conciencia autorial referirse a distintos espacios y situaciones sociales en Haití, así como escenificar diálogos entre el narrador y otros artistas y escritores haitianos. La pregunta por los modos de representación de la realidad tiene un lugar central en sus reflexiones. El narrador protagonista se encuentra en su viaje con dos tipos de pinturas: las que representan lugares en los que hay comida y vegetación en abundancia, y las que parecen copiar fielmente su entorno, al punto de difuminar la distinción entre el original y la copia. Al pintor de los cuadros del primer tipo, el narrador le pregunta por qué en sus pinturas no aparece la realidad que lo rodea. La respuesta que le da es: "qui veut accrocher dans son salon ce qu'il / peut voir par la fenêtre"²4 (84). La cuestión entonces es si el arte debe representar lo conocido, si debe ser mimético y realista, o si debe ser un espacio alternativo, de expresión y exploración del deseo. No se trata de una discusión en abstracto, sino de la pregunta por cómo debiera o podría ser un arte significativo para Haití. La respuesta del pintor sugiere que ese arte debiera crear nuevas imágenes, ofrecer a sus espectadores alternativas a la realidad cotidiana.

En otro momento, en una conversación con Gary Victor, novelista haitiano ficcionalizado en la novela de Laferrière, los personajes se preguntan cuál podría ser el tema "de una gran novela haitiana". Más que desde una respuesta directa, se aproximan a ella pensando primero en los grandes temas de otras literaturas nacionales o regionales:

J'ai discuté un moment avec lui à propos de ce qui pourrait être le sujet du grand roman haïtien. On a d'abord passé en revue les obsessions des autres peuples. Pour les Nord-Américains, on a pensé que c'était l'espace (le Far-West, la conquête de la Lune, la Route 66). Pour les SudAméricains, c'est le temps (Cent ans de solitude). Pour les Européens, c'est la guerre (deux guerres mondiales en un siècle, ça marque un esprit). Pour nous, c'est la faim. Le problème, me dit Victor, c'est qu'il est difficile d'en parler si on ne l'a pas connue. Et ceux qui l'ont vue de près ne sont pas forcément des écrivains. On ne parle pas d'avoir faim parce qu'on n'a pas mangé depuis un

\footnotetext{
22 "La escritura ha sido el recurso más importante que he tenido para darle sentido a mis pérdidas, incluyendo las muertes. He escrito sobre la muerte desde que empecé a escribir".

23 "Escribimos sobre los muertos para darle sentido a nuestras pérdidas, para que no nos acechen tanto, para convertir a los fantasmas en palabras, para transformar una ausencia en lenguaje".

${ }^{24}$ “QQuién quiere colgar en el salón de su casa lo que puede ver por la ventana?" (95).
} 
moment. On parle de quelqu'un qui n'a jamais mangé à sa faim de tout temps, ou juste assez pour survivre et en être obsédé. (I33-I34) $)^{25}$

El hambre entonces sería inenarrable porque quienes la sufren no pueden escribir sobre ella. Tal como ocurre con la muerte, el hambre solo podría narrarse en tercera persona. Sin embargo, uno de los recuerdos de infancia y juventud sobre los que vuelve reiteradamente el narrador es haber pasado hambre. No hambre de un día, sino el hambre a la que se refería Gary Victor, la de no saber cuándo se podrá comer, la de la escasez de comida como única certeza. Pero entre esos recuerdos y su presente median muchos años de comer bien en Canadá. A pesar de recordar el hambre, el narrador no pretende convertirla en el tema de su novela. Esta es, en términos formales, distinta a lo que habitualmente se concibe como una "gran novela nacional": la perspectiva narrativa es restringida y centrada en el "yo" del narrador, la hibridez genérica rompe con la posibilidad de crear un universo autónomo, las reflexiones sobre la realidad haitiana son parciales y, en el mejor de los casos, tienen un carácter exploratorio. Como señala el mismo Laferrière en una entrevista, en L'énigme du retour no hay "ningún espíritu militante" (Morency y Thibault I6, trad. de la autora).

En el transcurso de su viaje, el narrador se va dando cuenta de que, más que para representar un paisaje, había escrito "pour en faire encore partie"26 (I52). Reconoce, así, la literatura como un recurso para el retorno: "Le dictateur m'avait jeté à la porte de mon pays. Pour y retourner, je passe par la fenêtre du roman"”7 (I6I). Laferrière-personaje afirma que, a través de la escritura, ha podido compensar una serie de ausencias: la de su país en su vida, la suya en el escenario de Haití, la de Da, su abuela muerta, que "vit aujourd'hui /dans mes livres"28 (238). La escritura ha sido así un modo de confrontar y transformar la realidad impuesta por el dictador y de hacer presentes a los ausentes. Como señala Miraglia: "Si Aimé Césaire et Windsor Laferrière père se superposent dans l'imagination du narrateur, c'est parce qu'à l'instar de Césaire, et à la différence du père, Windsor Laferrière fils trouve dans l'écriture la possibilité de sauvegarder l'essentiel de lui-

\footnotetext{
25 "He estado hablando un momento con él sobre lo que podía ser el tema de una gran novela haitiana. Les pasamos revista primero a las obsesiones de los demás pueblos. Para los norteamericanos, pensamos que era el espacio (el lejano oeste, la conquista de la luna, la Ruta 66). Para lo suramericanos, es el tiempo (Cien años de soledad). Para los europeos, es la guerra (dos guerras mundiales en un siglo marcan). Para nosotros, el hambre. El problema -me dice Victor- es que resulta difícil hablar de hambre cuando no se ha conocido. Y quienes la han visto de cerca no son necesariamente escritores. No hablamos de tener hambre porque no se haya comido desde hace un rato. Hablamos de alguien que nunca jamás ha comido hasta saciarse, o sólo lo justo para sobrevivir y obsesionarse" (I5I).

26 "Para seguir formando parte de él" (I73).

${ }_{27}$ "El Dictador me había puesto en la puerta de la calle de mi propia tierra. Para volver, me cuelo por la ventana de la novela" (I73).

28 "vive hoy en mis libros" (268).
} 
même (et de son père) malgré la solitude et les difficultés de l'exil’²9 (86). Para Laferrière personaje la escritura constituye un recurso fundamental para confrontar las pérdidas y la distancia impuestas por el exilio.

\section{RELACIONES DE FILIACION LITERARIA}

La escritura de la gran novela haitiana -cuyo tema central, según Gary Victor personaje, sería el hambre- enfrenta las mismas dificultades que la de la muerte: quienes tienen la experiencia no pueden hablar de ella ya sea porque no son escritores o porque han muerto. Esto no significa que la literatura no pueda hablar del hambre o de la muerte, sino que no puede pretender hacerlo como si se encarnara totalmente esas experiencias. Al afán totalizador que conlleva la idea de una "gran novela" se opone en L'énigme du retour el proyecto literario personal del narrador: hacer de la escritura un puente para el retorno, que permita recuperar, aunque sea fragmentariamente, las memorias de un pasado fracturado por el exilio. Esta aproximación al arte y la literatura, así como a la figura del escritor, es muy distinta a la que se asocia con Aimé Césaire y sobre todo con el Cuaderno de un retorno al país natal. El largo poema busca representar la realidad antillana de la pobreza, el hambre y la explotación colonial. En el Cuaderno... el sujeto poético se alza como representante de los sin voz ("Mi boca será la boca de las desdichas que no tienen boca, mi voz, la libertad de las voces que se desploman en la mazmorra de la desesperación" 44). En L'énigme du retour el protagonista recuerda que cuando leyó de joven el poema de Césaire no pudo entender por qué causaba tanto entusiasmo, siendo que él lo encontraba prosaico y rabioso ("Je l'avais trouvé bien fade à la première lecture... Je voyais bien que c'était l'œuvre d'un homme intelligent traversé par une terrible colère" 57). ${ }^{30}$ Pese a esa distancia inicial, durante todo su exilio hubo dos cosas de las que no se separó nunca: una carta de su madre y el ejemplar del Cuaderno... con el que partió de Haití. Su relación con el poema y con Césaire es ambivalente, del mismo modo que el recuerdo de su padre. El tono rabioso y militante que para Laferrière conecta a su padre con Césaire es el mismo que lo distancia de ellos. Mientras los dos primeros pertenecen a un momento histórico en que los intelectuales confiaban en su capacidad para transformar el mundo, el narrador identifica

\footnotetext{
29 "Si Aimé Césaire y Windsor Laferrière padre se superponen en la imaginación del narrador, es porque del mismo modo que Césaire y a diferencia del padre, Windsor Laferrière hijo encuentra en la escritura la posibilidad de salvaguardar lo esencial de sí mismo (y de su padre) pese a la soledad y a las dificultades del exilio" (trad. de la autora).

30 "Me parecieron muy insulsos [los poemas]... Entendía muy bien que era la obra de un hombre inteligente ganado por una terrible rabia" (66-67).
} 
su lugaren una generación que, como parte de un giro postmoderno, desconfía y se distancia de esa construcción de la figura del escritor como intelectual público. ${ }^{3+}$

Las secciones del Cuaderno... que sí conmueven a Laferrière y que explican que no se deshaga nunca del poema, son aquellas que ofrecen una visión poética de la realidad caribeña, iluminando aspectos de su propia experiencia isleña. En esa experiencia también tienen cabida la conciencia de la pobreza, la injusticia, la explotación y el hambre, observadas críticamente por el narrador a lo largo de su recorrido. Sus diferencias con lo que encuentra en el Cuaderno... son sobre todo de tono y perspectiva. De tono porque se aleja de la indignación más o menos grandilocuente. De perspectiva porque no pretende ser una conciencia iluminada capaz de reconocer y denunciar esos males, más bien se construye como un testigo que solo tiene el poder de una palabra limitada en sus alcances e imprecisa en sus posibilidades. Al final del viaje -y de la novela- el protagonista "desliza" el ejemplar del Cuaderno... en el bolso de su sobrino Dany, quien también quiere ser escritor. El sobrino, que tiene el mismo nombre que él, aparece como parte de una nueva generación que debe decidir si quedarse o irse de Haití. Lo más parecido a un consejo de su tío es el ejemplar del Cuaderno... que él dejará en su bolso y que según el narrador resulta un libro más útil cuando se parte que cuando se retorna. De modo análogo a cuando el narrador siente alivio de no tener que cargar con el contenido de la maleta de su padre -es decir, con el peso de su destino-, tampoco cree que pueda hacer una transferencia consciente de su experiencia a su sobrino: "J'ai glissé dans la sacoche de mon neveu/ le vieux recueil gondolé par la pluie/ du Cahier d'un retour au pays natal. C'est avant de partir qu'on en a besoin. Pas au retour"32 (259). El acto de deslizar (glisser) el ejemplar sin que el sobrino se dé cuenta expresa que no quiere ejercer una influencia demasiado directa sobre él.

En The Art of Death, Danticat parece mucho menos amenazada que Laferrière en L'énigme du retour por la posibilidad de heredar el destino de su madre o de parecerse más a ella. Del mismo modo, su relación con el legado de escritoras que juegan el rol de "madres literarias" en su proyecto escritural carece de la ambivalencia que caracteriza la relación de Laferrière con Césaire. En una entrevista Danticat destaca la importancia de Toni Morrison y en particular de su novela Sula: "I

\footnotetext{
${ }^{31}$ Para Michael Dash, Danticat puede ser situada entre medio de dos tradiciones de la literatura haitiana posterior a la ocupación estadounidense de 1915 . Por un lado está la narrativa de protesta a la ocupación, que veía en la literatura una forma de acción contra la presencia y los abusos de Estados Unidos. Los escritores más importantes de esta corriente son Jacques Roumain y Jacques-Stephen Alexis. Por otro lado está el periodo que se inicia a partir de r96o, en que se habla del giro postmoderno de la literatura haitiana. En esta nueva etapa se eclipsa la confianza en la palabra del escritorrevolucionario y en su capacidad de transformar la realidad. Para Dash Laferrière es un claro representante del giro postmoderno (3I-32).

32 "He metido en el bolsón de mi sobrino/ la vieja colección abarquillada por la lluvia/ del Cuaderno de un regreso a la tierra natal./ Antes de partir es cuando hace falta./ No al regreso" (289).
} 
read Toni Morrison's Sula a lot. I read it for time. I read it for setting. I read it for every book I write. I read it for language and I read it for how much she squeezes in that little book without leaving anything out. It is the godmother of every one of my books"'33 (Jones).

Las distintas formas en las que Danticat y Laferrière configuran sus relaciones de filiación literaria recuerdan lo que Gilbert y Gubar propusieron sobre los procesos de creación de escritores hombres y mujeres. Si bien el estudio de estas críticas se centra en las estrategias de "autorización" de escritoras victorianas, su propuesta en relación con los modelos de creación de varones y mujeres también parece válida para las diferencias que se observan entre Danticat y Laferrière. Según Gilbert y Gubar, el modelo de creación literaria centrado en torno a la noción de la "ansiedad de influencia" funciona bien en el caso de los escritores varones, quienes frente a la presencia de ancestros literarios reaccionan con el temor de no poder tener una voz propia-de ahí su necesidad de matar a sus padres literarios, el complejo edípico que según Bloom impulsa el desarrollo de la literatura-. En el caso de las escritoras, y en particular de las victorianas, más que un temor a sucumbir a la influencia de ancestros literarios, lo que operaría sería una "ansiedad de autoría". Esta consistiría en el temor a no poder validarse como autoras debido a la inexistencia de escritoras mujeres reconocidas como tales. Para autorizarse, entonces, las autoras recurrirían más a la reconstrucción de genealogías y a la visibilización de otras escritoras, que a su negación.

Tanto para Danticat como para Laferrière la presencia de otros escritores y escritoras es fundamental para la creación de su obra. Si bien he destacado aquí el vínculo de Danticat con escritoras afroestadounidenses y haitianas, también hay muchos escritores que ella reconoce como fundamentales, como Jacques Roumain, con quien señala que mantuvo una conversación silenciosa hasta que la hizo pública con el título de su libro The Dew Breaker (2004), que alude a Masters of the Dew, el nombre en inglés de Gouverneurs de la rosée ("Daughters of Memory" 62). Laferrière por su parte suele incorporar a escritores que admira en sus libros (Morency y Thibault), pero destacando que sus elecciones tienen que ver con su biblioteca personal y que su propia identidad le debe más a lo que son sus lectores que al país del que viene. Como muestra Elena Biholaru en su artículo dedicado a la identidad en Laferrière, este quiere ser leído como un autor de literatura a secas y no como un escritor migrante, haitiano o negro. Reclama constantemente para sí su derecho a escribir de temas diversos, a veces vinculados con su país de origen, otras no; en el fondo, a nutrir su literatura de la experiencia propia, ajena y también de la fantasía. En ese sentido, Laferrière es muy

\footnotetext{
33 "Leo muchas veces Sula de Toni Morrison. La leo por el tratamiento del tiempo. La leo por la ambientación. La leo cada vez que escribo un libro. La leo por el lenguaje y la leo por todo lo que logra explotar en ese pequeño libro, sin dejar nada fuera. Sula es la madrina de cada uno de mis libros" (trad. de la autora).
} 
crítico de las demandas de autenticidad y representatividad que se les suele plantear a los que se ha denominado como "escritores étnicos" (Stecher y Zapata).

Las diferencias que hemos señalado en la forma en que Danticat y Laferrière se relacionan con la tradición literaria caribeña y haitiana no afectan en absoluto la relación entre ambos, que en diversas ocasioneshan expresado su cariño y admiración mutua. Laferrière escribió el prólogo al primer volumen de estudios sobre la obra de Danticat, editado por Martin Munro y le dedicó su libro Journal d’un écrivain en pyjama. Danticat, por su parte, defiende a Laferrière de las críticas que le hicieron en Canadá por no haberse quedado en Haití después del terremoto y piensa en L'énigme du retour como una novela testimonio de lo que fue su país antes de la devastación: "L'énigme du retour was the first novel I read after the earthquake. I devoured it in a few hours. Unlike many of Dany's other books, it wasn't funny. I didn't laugh. I cried. The novel it turns out, is a love poem, a love song to a Haiti that no longer exists, the Haiti of before the earthquake...”34 (I6I).

El foco de este artículo ha estado puesto en las relaciones con padres/madres biológicos y literarios, tal como se piensan sobre todo a partir de la experiencia de la muerte y del desafío que plantea su representación literaria. Coincido con Clitandreen que "A significant part of Danticat's search for home is also a search for her literary ancestors to bridge the relationship between reader and writer severed by Duvalier"35 (I83). Las últimas reflexiones del texto apuntan a que el esfuerzo por reconstruir herencias y reconocer filiaciones se da también en un nivel diacrónico, es decir con los compañeros y compañeras del amplio campo literario de la diáspora. La presencia de dos figuras tan importantes como Danticat y Laferrière en ese espacio, los vínculos de mutuo reconocimiento entre ambos, y también las diferencias entre sus proyectos dan cuenta de la inmensa heterogeneidad, riqueza y complejidad de esta producción literaria.

\section{REFERENCIAS}

Aiello, Francisco. "Elaboraciones de la cultura haitiana en Pays sans chapeau de Dany Laferrière". Literatura: Teoría, Historia, Crítica, vol. I5, nº 2, 2013,167-I80.

Aiello, Francisco. "La reelaboración de la tradición caribeña en L'énigme du retour de Dany Laferrière". Desarraigos: de la experiencia a la escritura: estudios argentinos de literatura francesa

\footnotetext{
34 "El enigma del regreso fue la primera novela que leí después del terremoto. La devoré en un par de horas. A diferencia de muchos de los otros libros de Dany, este no era cómico. No me hizo reír, sino llorar. Resulta que la novela es un poema de amor, una canción de amor a un Haití que ya no existe, el Haití previo al terremoto" (Crear en peligro i69).

35 "Una parte significativa de la búsqueda de hogar de Danticat es también una búsqueda de sus ancestros literarios que busca reconstruir la relación entre lector y escritor rota por Duvalier" (trad. de la autora).
} 
y francófona. Compilado por Susana G. Artal; Francisco Aiello. Prólogo de Susana G. Artal. Batán: Letra Sudaca Ediciones, 2015.

Biholaru, Elena-Camelia. "Lidentité - une quête à travers l'écriture (Dany Laferrière)". ANADISS. Revue du Centre de Recherche Analyse du discours. Journal of the Discourse Analysis Research Centre, $n^{\circ}$ 19, 2015, 66-77.

Butler, Judith. Precarious Life. The Powers of Mourning and Violence. London-New York: Verso, 2004.

Césaire, Aimé. "Cuaderno de un retorno a la tierra natal". Trad. José Luis Rivas. Para leer a Aimé Césaire. Selección y presentación de Philippe Ollé-Laprune. México: FCE, 2008.

Ching, Selao. "L'énigme des pères. Laferrière sans valise ni cahier". Voix et Images, vol. 4I n. ${ }^{\text {3 }}$, 20I6, I63-177.

Clitandre, Nadège T. "Mapping the Echo Chamber: Edwidge Danticat and the Thematic Trilogy of Birth, Separation, and Death". Palimpsest: A Journal on Women, Gender, and the Black International, $\mathrm{n}^{\mathrm{o}}$ 3, Issue 2, 2014, 170-190.

Danticat, Edwidge. Create Dangerously. The Immigrant Writer at Work. New Jersey: Princeton UP, 2010.

Danticat, Edwidge. "LòtBòDlo: The Other Side of the Water". Haiti after the Earthquake. Ed. Paul Farmer. Kindle ed., Public Affairs, 2oIr.

Danticat, Edwidge. The Art of Death. Writing the Final Story. Minneapolis: Graywolf Press, 2017.

Danticat, Edwidge. Crear en peligro. El trabajo del artista migrante. Trad. Lucía Stecher y Thomas Rothe. Santiago de Chile: Banda Propia editoras, 2019.

Dash, Michael. "Danticat and her Haitian Precurssors". Edwidge Danticat. A Reader's Guide. Ed. Martin Munro. Foreword by Dany Laferrière. Charlotesville: University of Virginia Press, 2010.

Gilbert, Sandra y Susan Gubar. The Madwoman in the Attic: The Woman Writer and the NineteenthCentury Literary Imagination. New Haven: Yale UP, zooo.

Jones, Kima. "The Rumpus Interview with Edwidge Danticat". The Rumpus, January Ist, 20I4, https://cutt.ly/UTr3RYe (fecha de consulta: Io/ro/2020). 
Laferrière, Dany. L'énigme du retour. Paris: Grasset, 2009.

Laferrière, Dany. El enigma del regreso. Traducción Elena Michelle Cano e Íñigo Sánchez Paños. Madrid : Alianza, 2012.

Laferrière, Dany. Pays sans chapeau. Paris : Zulma, 2018.

Mathis-Moser, Ursula. Dany Laferrière. La dérive américaine. Montréal : VLB, 2003.

Miraglia, Anne Marie. "Le retour à la terre et l'absence du père dans Pays sans chapeau et L'énigme du retour de Dany Laferrière. Voix et images, n 36 (2), 20II, 8I-92.

Morency, J. \& Thibeault, J. "Entretien avec Dany Laferrière". Voix et Images, n 36 (2), 20II, I5-23.

Naipaul, V.S. The Enigma of Arrival. Kindle ed., First Vintage Books Edition, 1988.

Stecher, Lucía. Narrativas migrantes del Caribe. Michelle Cliff, Jamaica Kincaid y Edwidge Danticat. Buenos Aires: Corregidor, 2016.

Stecher, Lucía y Claudia Zapata. "Representación y memoria en escrituras indígenas y afrodescendientes contemporáneas". Revista Casa de las Américas, nº 280, 2015, 3-20.

Viart, Dominique. "El relato de filiación. Ética de la restitución contra deber de memoria en la literatura contemporánea". Trad. Macarena Miranda. Cuadernos Lírico, no 20, 2019, I68-I9I. 